\title{
Application of Electric Automation Control Technology in Power System
}

\author{
Haiyan Wang \\ Shengli College China University of Petroleum, Dongying, 257000, Shandong, China \\ why1528@126.com
}

Keywords: Keywords: power system; electrification control; automatic control; intelligent electrical system.

\begin{abstract}
With the continuous development of society, the demand for electrical energy continues to rise, and people have put forward higher requirements for the operation quality of power systems. In order to improve the safety and stability of power system operation, people began to apply power automation technology to the power system, and achieved significant results. Power automation technology has gradually become the focus of power company research. This article briefly introduces the power automation technology, expounds the value of power automation technology application, and analyzes the specific application of power automation technology, hoping to provide some help for the stable operation of the power system.
\end{abstract}

\section{Introduction}

With the continuous expansion of people's production and living scale, people pay more attention to the operation stability and production quality of the power system. From the perspective of the development of automation, electrical automation technology is the latest product of the continuous development of science and technology. With the further improvement of computer technology, electrical automation technology will usher in a new round of technological innovation, and the level of electrical automation It also determines the overall strength of the country. In recent years, the level of electrical automation has been continuously improved, making the power system enter a new high-speed development period. Electrical automation is also gradually becoming more specialized in the process of continuous innovation and reform, which plays an important role in promoting the development of smart grids in my country.

Electrical engineering automation technology refers to the innovation of the function and technical means of power secondary equipment, so that the equipment can be automatically monitored during operation. It greatly improves the production efficiency of the enterprise, reduces the operating cost of the equipment, and makes the power system more stable., Reliable and safe. Increasing the efficiency of automated management of operating equipment makes it more and more important for power system operating data to be reasonably analyzed. At the same time, electrical engineering automation has powerful processing functions in terms of power system operation data processing. For example, in the statistics of power system information data, electrical automation technology can be used for statistics, thereby improving the accuracy of data statistics, and greatly improving the efficiency of statistical work compared with manual statistics. In addition, in the operation of the power system, electrical engineering automation technology can be used for fault maintenance, analysis of problems existing during operation, and timely solutions to find solutions to ensure safe and stable operation of the power system. This article analyzes the current status of the development of electrical automation in my country's power system, and studies the role of electrical automation in electrical systems [1]. 


\section{Electrical automation control system}

\subsection{Overall system architecture}

$110 \mathrm{kV}$ Xinsheng Substation Intelligent Auxiliary Control System mainly uses the latest technologies such as Internet of Things, communication and sensor networks, three-dimensional visualization and virtual simulation, intelligent analysis and multi-dimensional linkage, cloud computing and GIS spatial information, etc., relying on various sensing and identification equipment Completed real-time monitoring, data analysis, alarm linkage and three-dimensional visual display of substation environment, power and equipment hot spots, and truly built intelligent substation integrated information management including intelligent building, operation assistance, maintenance assistance, asset management and other functions The system realizes the data interaction and sharing with the integrated monitoring system of the substation, and provides important auxiliary support for the "big operation" and "large maintenance" of the substation. The system will also complete the integration with SG-ERP, GIS, control and " The integration of the "three sets and five major" systems, and the continuous deepening of the application, will eventually achieve the complete integration of power grid power flow, information flow and business flow. This system is based on three-dimensional visualization and Internet of Things technology, with smart sensors, high-definition network video probes, FRID tags, etc. as the main material foundations to build a substation intelligent status monitoring system. The system structure diagram is shown in Figure 1 below.

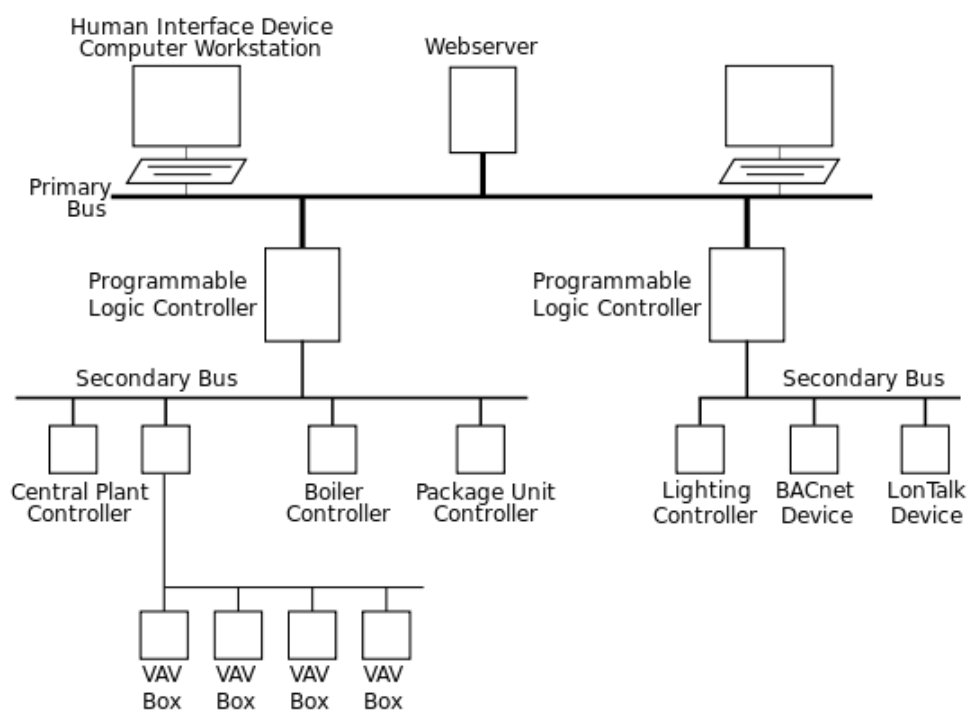

Fig.1 Structure diagram of electrical automation system

\subsection{System technical architecture}

The technical architecture of the system is divided into an acquisition layer, a processing layer, an application layer, and an external interface, as shown in Figure 2. The collection layer realizes the collection of various sensor data in the station; the processing layer processes the collected data to realize data monitoring, alarm and record query; the application layer provides data display and interaction relying on three-dimensional scenes; the external interface provides a platform and external system Communication transmission and resource exchange between. 


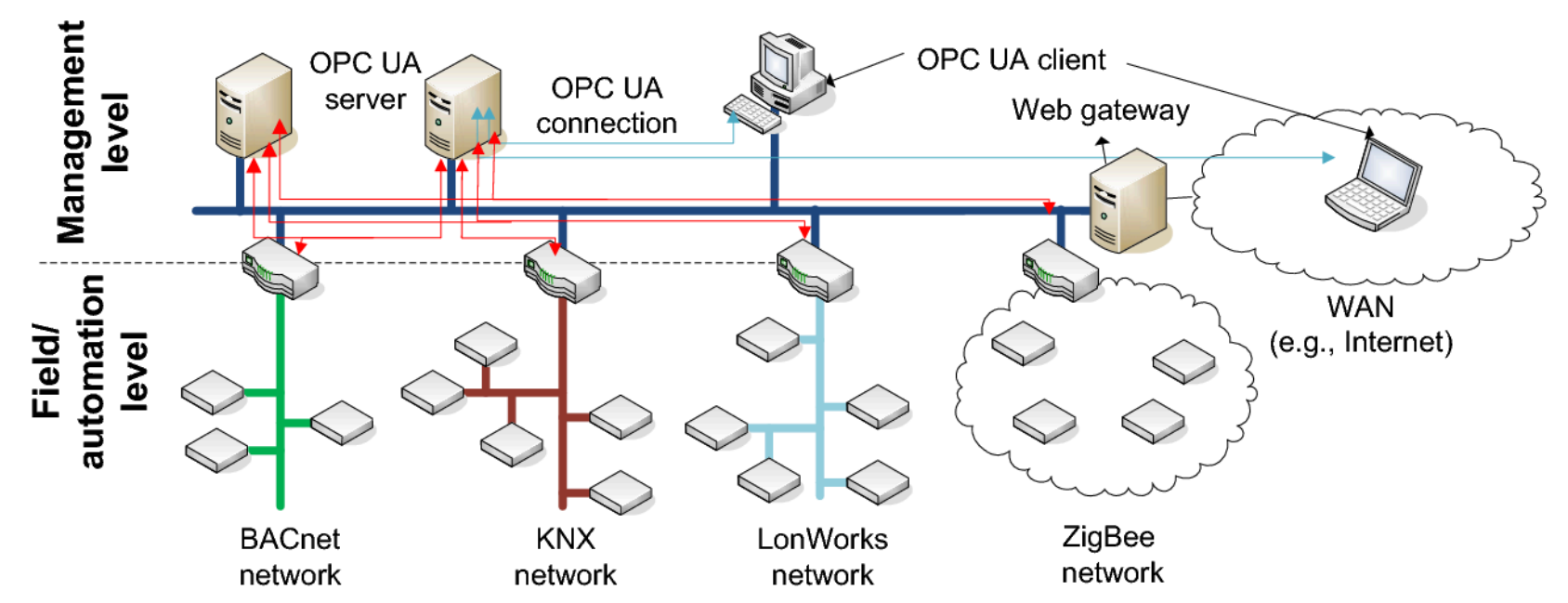

Fig.2 System technical architecture

\subsection{System network architecture}

According to the layered structure system of intelligent substation, the integrated automation system includes process layer, bay layer and station control layer, as shown in Figure 3.

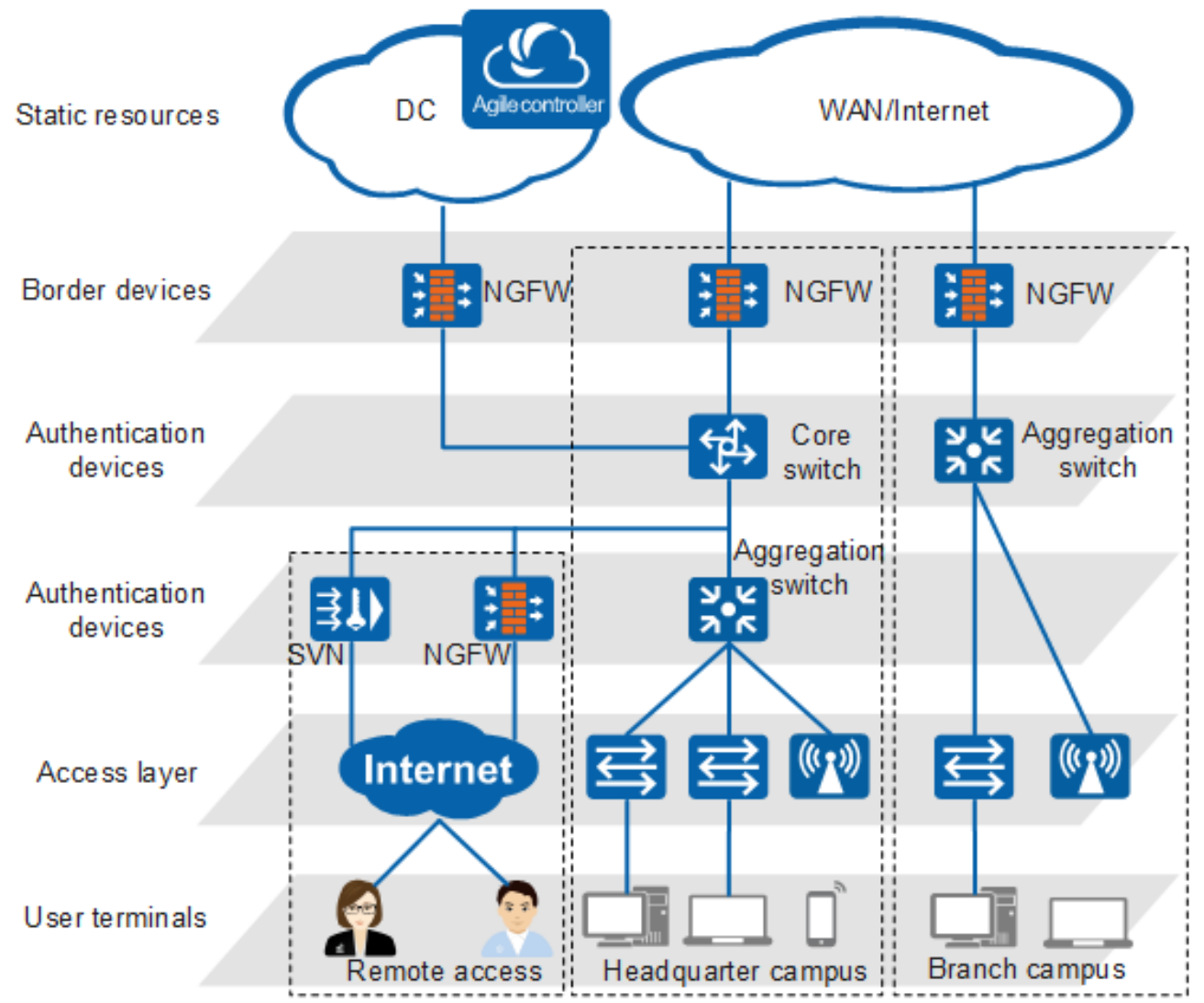

Fig. 3 Network architecture

The intelligent auxiliary control system draws on the concept of the Internet of Things, and takes people entering and leaving the substation and various types of equipment and facilities as the perception level of the Internet of Things; the communication network in the substation is used as the network transmission level of the Internet of Things; The application layer analyzes, processes and processes these comprehensive information to form an integrated three-dimensional visualization, linkage control and intelligent analysis. The "process layer" corresponds to the "perception layer" of the Internet of Things. It uses RS485 bus, Ethernet, wireless and other communication methods to realize data collection for various sensing devices and complete device status monitoring. The integrated access equipment is located at the "interval layer", which realizes the collection of 
monitoring data and the transmission of interactive control information; video monitoring data and substation inspection information (via unidirectional isolation devices) are directly transmitted from the process layer to the station control layer. The "station control layer" corresponds to the "application layer" of the Internet of Things. Related data is connected to the system platform at the station control layer, and the system platform receives, analyzes, alarms linkage, and visualizes the display in a unified manner. In addition, the system platform is interconnected with the integrated automation system via a one-way isolation device to provide auxiliary support for intelligent operation and maintenance of the substation [2].

\section{Analysis of technical points}

(1) After adjustment, you can find the laws and characteristics of the operation of various parts and systems, and summarize and summarize them. After corresponding practice, under the guidance of high efficiency and energy saving, the power system automation construction mode with the highest operating safety factor, the lowest energy consumption, the best power supply quality and the most reasonable structure can be selected [3].

(2) On the basis of power system automation, set up relevant technical examples, analyze its feasibility and carefully summarize the real-time status and effect of power system operation, and implement the decision and regulation of power automation system based on the obtained data to make it Better control of the overall system and parts.

(3) The basic operation of power system automation construction mainly depends on the safety and reliability of the power system in operation. This requires the electronic system to guarantee its safety to the maximum extent and make the overall system run more smoothly. In the work of the power system, relevant personnel should conduct systematic evaluation and analysis, strictly monitor and collect the safety during operation, the corresponding machinery and parts, and scientifically process the collected data. The data come from to make the most accurate judgment, 0 guarantees that the overall power system can run smoothly.

(4) The mechanization of the production methods used in the traditional power system is very backward. If you want to transform into a modern production method, you must establish and apply an automated power system. Power system automation minimizes the incidence of failures, reduces large-scale blackouts, and better lays the foundation for achieving goals.

\section{Electrical engineering automation technology in power system operation applications}

\subsection{Application of artificial intelligence technology in power system operation}

During the operation of the power system, some system failures will inevitably occur. In order to eliminate the faults in time, people need to check and maintain each link in the operation of the power grid. This requires a lot of manpower and material resources, and this method may not be solved in time. problem. In the troubleshooting of the system, through the use of electrical engineering automation technology, the feeder safety automation terminal FTU is used to analyze the power system failure, the DTU terminal is connected to the string 485 , and the communication base station is used to pass the information to the power plant through the router. In the power plant detection center, you can find power system problems in time and repair the faults in time, thereby ensuring the normal operation of the power system, saving the cost of power companies, and reducing the impact on people's daily lives.

\subsection{Application of power grid technology in power system operation}

At present, with the continuous development of China's power grid technology, electronic information technology has been widely used, which has brought opportunities to the development of power grid technology. The application of power grid technology in the operation of the power system has expanded the distribution range of the power grid and made the Dispatch meets standard requirements. Due to the wide coverage of the power grid and the large difference in transmission 
power in different regions, the distribution network has $13 \mathrm{kV}, 4 \mathrm{kV}, 240 \mathrm{~V}, 120 \mathrm{~V}$, etc. If the traditional management method is adopted, the operation cost will be wasted, and the use of electrical engineering automation technology Optimal dispatching of power of different powers improves the efficiency of power system data processing and ensures stable operation of the power system[4].

\subsection{Power automation monitoring system}

For now, my country's power automation monitoring system has been widely used in the operation of power systems and plays an irreplaceable role. The application of automated online detection technology to the power system can promptly detect the insulation failure of the power equipment operation, ensure the safe operation of the equipment, and realize the management of information such as field equipment data collection, digital communication and equipment maintenance in the power supply system. All along, my country has invested a lot of manpower and material resources in the study of power automation monitoring technology, and has achieved tremendous results in this regard. The development, utilization and development of power automation monitoring technology not only improves the automation and intelligence of power system operation management, but also realizes the functions of power system state information collection, processing, transmission and control. The application of automated monitoring technology has shortened the time for processing information and data, which not only improves work efficiency, but also reduces the cost of power companies, laying a good foundation for the continuous development of power system automation [5].

\subsection{Application of fuzzy logic control technology}

Fuzzy logic control technology plays an active role in the current power system automation control process. The fuzzy method is mainly used to control the power system. The operation mode is relatively simple and the technicians are easy to master. In the process of practical application of fuzzy method, the support of its non-linear and uncertain system makes the fuzzy logic control technology better serve the power system. By comparing fuzzy logic control technology with expert system control technology, it can be found that it has a high randomness. It does not depend on the data model of the controlled object. It can control many complex logic problems under the direct application of fuzzy inference methods. Compared with some conventional control technologies, it can be found that the fuzzy logic control technology effectively improves the control quality of intelligent technology, and at the same time reduces the risk of the power system. It has made breakthrough progress in the response effect, but it also needs to be noted There are certain problems in itself, mainly because the stability of the technology itself is not high enough, it is prone to overshoot problems, and once the power system operation link fails, the application of fuzzy logic control technology will unconsciously increase the system operation Difficulty. Therefore, the fuzzy logic control technology is used in the automatic control process of the power system, and it needs to be matched with other effective intelligent technologies in order to fully exert the value and role of the technology [6].

\subsection{Application of integrated intelligent system}

The integrated intelligent system has greater control potential, and the level of intelligence is also higher. Its internal combination is more complicated, including cross-linking between power systems, intelligent control systems and technologies. For the current power system, it is still in a relatively primary stage of development, and the development and research work for the automation control of the power system has never stopped. Experts and scholars integrate expert systems and neural network systems to develop new integrated intelligent systems. The wide application of this system in the power system will be able to play a positive role in optimizing the overall mode of power system operation. The neural network in the fuzzy system can adopt a new and high-quality processing method to enhance the processing level of unstructured information. Therefore, a good combination of artificial neural network and fuzzy logic has a certain foundation in technical 
cooperation. The emphasis is different. The former is suitable for low-level computing, while the latter has a positive significance for solving non-statistical problems. The combination of the two has improved the application level of intelligent technology.

\section{Conclusion}

The power system is the foundation that supports my country's economic development. In recent years, in order to ensure the stability and safety of power system operation, people have gradually applied electrical automation control technology to it, which has reduced power system operation failures and improved the stability and safety of power system operations. At the same time, the application of electrical automation control technology in the power system can greatly demonstrate the value of electrical automation control technology itself, promote the development of my country's power industry, and achieve good economic benefits.

\section{References}

[1] Eltag, K. Aslamx, M. S., \& Ullah, R. Dynamic stability enhancement using fuzzy pid control technology for power system. International Journal of Control Automation and Systems, Vol. 17(2019) No.1, p. 234-242.

[2] Yang, T. A new control framework of electric power steering system based on admittance control. IEEE Transactions on Control Systems Technology, Vol. 23(2015) No.2, p. 762-769.

[3] Hu, L. Wang, Z. Rahman, I., \& Liu, X. A constrained optimization approach to dynamic state estimation for power systems including pmu and missing measurements. IEEE Transactions on Control Systems Technology, Vol. 24(2016) No.2, p. 703-710.

[4] Gouveia, C. Rua, D. Soares, F. J., Moreira, C., Matos, P. G., \& Lopes, J. A. P. Development and implementation of portuguese smart distribution system. Electric Power Systems Research, Vol. 120(2015) No.3, p. 150-162.

[5] Tang, A. Shao, Y. Huang, Y., \& Xu, Q. A new topology of the distributed power flow controller and its electromagnetic transient characteristics. Electric Power Systems Research, Vol. 163(2018) No.10, p. 280-287.

[6] Roy, K. Chatterjee, A. Chatterjee, D., \& Ganguli, A. K. A photovoltaic-based improved excitation control strategy of three-phase self-excited induction generator suitable for wind power generation. Electric Power Components and Systems, Vol. 43(2015) No.7, p. 1-9. 